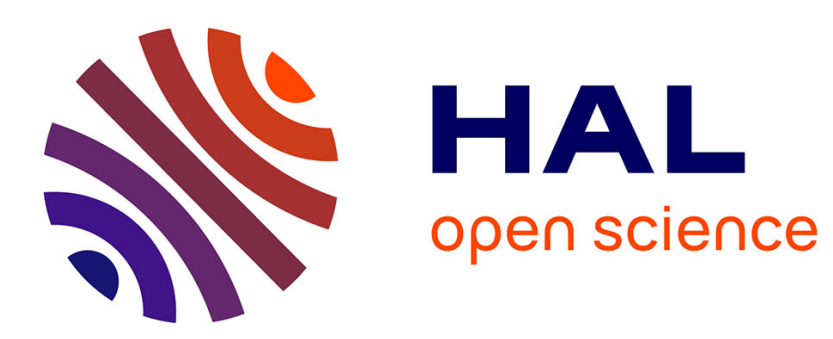

\title{
Cutting Forces Modeling in Finish Turning of Inconel 718 Alloy with Round Inserts
}

Sébastien Campocasso, Jean-Philippe Costes, Gérard Poulachon, Alexis

Perez-Duarte

\section{- To cite this version:}

Sébastien Campocasso, Jean-Philippe Costes, Gérard Poulachon, Alexis Perez-Duarte. Cutting Forces Modeling in Finish Turning of Inconel 718 Alloy with Round Inserts. 13th CIRP Conference on Modelling of Machining Operations, May 2011, Sintra, Portugal. pp.75-84, 10.4028/www.scientific.net/AMR.223.75 . hal-00724304

\section{HAL Id: hal-00724304 \\ https://hal.science/hal-00724304}

Submitted on 20 Aug 2012

HAL is a multi-disciplinary open access archive for the deposit and dissemination of scientific research documents, whether they are published or not. The documents may come from teaching and research institutions in France or abroad, or from public or private research centers.
L'archive ouverte pluridisciplinaire HAL, est destinée au dépôt et à la diffusion de documents scientifiques de niveau recherche, publiés ou non, émanant des établissements d'enseignement et de recherche français ou étrangers, des laboratoires publics ou privés. 


\title{
Cutting Forces Modeling in Finish Turning of Inconel 718 Alloy with Round Inserts
}

\author{
Sébastien Campocasso ${ }^{1, \mathrm{a}}$, Jean-Philippe Costes ${ }^{1, \mathrm{~b}}$, Gérard Poulachon ${ }^{1, \mathrm{c}}$ and Alexis \\ Perez-Duarte ${ }^{2, \mathrm{~d}}$ \\ ${ }^{1}$ Arts et Metiers ParisTech, LaBoMaP, 71250 Cluny, France \\ ${ }^{2}$ SNECMA, Rue Henri Auguste Desbruères BP81, 91003 Evry, France
}
${ }^{a}$ sebastien.campocasso@ensam.eu, ${ }^{b}$ jean-philippe.costes@ensam.eu, ${ }^{c}$ gerard.poulachon@ensam.eu, dalexis.perez-duarte@snecma.fr

Keywords: Cutting Forces Modeling, Finish Turning, Round Inserts, Inverse Identification, Homogeneous Matrices, Scaling Effect, Inconel 718

\begin{abstract}
In turning, the applied forces have to be known as accurately as possible, especially in the case of difficult-to-cut materials for aircraft workpieces finishing operations.

Traditionally, edge discretisation methodology based on local cutting laws is used to determine the cutting forces and results are usually considered suitable. Nevertheless, only the rake face is considered in most of studies and the cutting relations are determined by direct identification with a straight edge.

This study deals with finishing operations of Inconel 718 alloy with one type of round insert. The main objective is to formulate a novel cutting forces model, taking into account the clearance face. First, a generic model based on a geometrical description using homogeneous matrix transformation is presented. Then, cutting coefficients are identified by inverse identification from experimental measurements distributed with an orthogonal design experiment including tool wear.

Finally, modeling and experimental values of the cutting forces are compared and the identified model is analysed.
\end{abstract}

\section{Introduction}

In the context of aircraft engine manufacturing, calculation of cutting forces enters a global approach of simulation, which should ensure the workpiece performances.

Profiling operations with round inserts cannot be modeled by classical cutting forces models, due to the important variation of cutting conditions along the active cutting edge. Edge discretisation principle is often used for modeling milling operations [1-5], but it can be also applied to turning. Then, local cutting conditions - as the uncut chip thickness $h$ - are taken into account in the cutting relations used to calculate the local cutting forces.

Local forces can be expressed as tangential, radial and axial in relation with the tool axis [1-2] or as normal and tangential to the rake face [3]. A local basis linked to the cutting edge and the rake face is proposed by Bissey-Breton et al. [4]; it allows a physical explanation to the local forces (normal pressure and tangent friction forces applied on the rake face) to be given.

However, in this latest case, only the rake face is considered since only roughing operations are studied. Yücesan and Altintas [5] introduced a local basis linked to the clearance face and took into account the flank forces. 
Generally, orthogonal and/or oblique cutting operations are used to determine cutting relations [2,4]; but the development of numerical simulations has induced progress in inverse identification in order to determine local laws [6] or coefficients [7]. So, identifications from complex cutting measurements become possible.

The aim of this study is to identify a cutting model by using only round inserts. Since the uncut chip thickness varied along the active cutting edge, the discretisation principle has been chosen. The methodology has consisted in: first, describing discretised cutting geometry and then, calculating global forces by summation of local forces applied on each segment of the discretisation. Coefficients of the local model have been identified by comparison between measured and calculated global forces (inverse identification). The particularities of the model used are that the clearance face and the scaling effect $[3,8]$ are taken into account.

\section{Geometrical modeling of turning operations with round inserts}

The aim of this section is to describe cutting geometry in a coordinate system parallel to the machine axis [9] (the considered machine is a rear turret lathe). Indeed, cutting forces are experimentally measured in the machine axis reference and it is also the reference for primary and feed motions, which are used for the calculation of working cutting angles [10-11].

In this study, coordinate systems, taking into account an origin, are preferred to classical vector basis. The cutting edge is assumed to be circular with a radius $r_{\epsilon}$.

Parameterisation and coordinate systems definition. Let $n_{s}$ be the number of segments of the discretisation and $M$ the current point on the cutting edge localized by its angular coordinate $\theta$. Then, the cutting edge is characterized by $n_{s}$ points $M(\theta)$ and $2 \cdot n_{s}$ coordinate systems $\mathcal{R}_{\gamma}=\left(M(\theta), \mathbf{a}, \mathbf{n}_{\gamma}, \mathbf{g}_{\gamma}\right)$ and $\mathcal{R}_{\alpha}=\left(M(\theta), \mathbf{a}, \mathbf{n}_{\alpha}, \mathbf{g}_{\alpha}\right)$, respectively linked to the rake face $\mathcal{A}_{\gamma}$ and the clearance face $\mathcal{A}_{\alpha}$. The vector $\mathbf{a}$ is tangential to the edge and $\mathbf{n}$ is normal to the considered surface [4]. Let $O$ be the center of the circle.

Angles $\gamma^{\mathrm{TH}}$ and $\lambda^{\mathrm{TH}}$ (Fig. 1) define the positioning of the insert on the tool holder. These angles are not normalised [10]; however, they are commonly used for inserts with negative basic shape [12-13].

Angles $\gamma_{\mathrm{n}}^{\mathrm{E}}$ and $\alpha_{\mathrm{n}}^{\mathrm{E}}$ (Fig. 2) define the local cutting angles given by sintering or grinding; these angles could be variable along the edge.

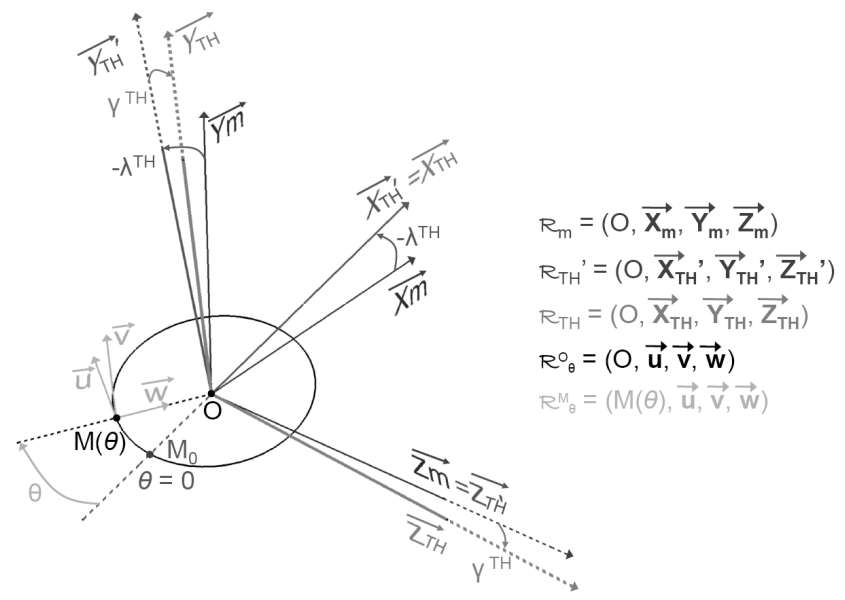

Fig. 1: Global coordinate systems:

Tool holder positioning and circular edge.

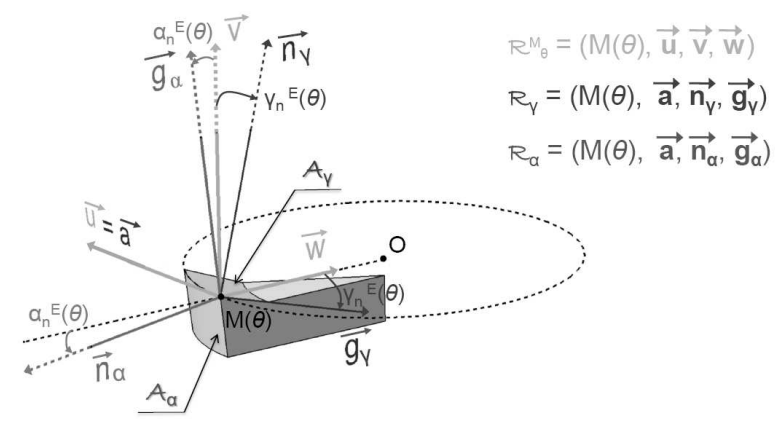

Fig. 2: Local coordinate systems:

Cutting angles of the insert. 
Homogeneous matrix transformation. The use of homogeneous matrices allows describing global and local cutting geometries and edge shape with the same model, avoiding a standalone parametric representation $[2,14]$. The change of coordinate system matrix from $\mathcal{R}_{1}$ to $\mathcal{R}_{2}$ is denoted $\mathcal{M}_{\mathcal{R}_{1} / \mathcal{R}_{2}}$.

Positioning of the insert on the tool holder (Fig. 1).

$$
\begin{aligned}
\mathcal{M}_{\mathcal{R}_{m} / \mathcal{R}_{T H}^{\prime}} & =\left(\begin{array}{cccc}
\cos \left(-\lambda^{T H}\right) & -\sin \left(-\lambda^{T H}\right) & 0 & 0 \\
\sin \left(-\lambda^{T H}\right) & \cos \left(-\lambda^{T H}\right) & 0 & 0 \\
0 & 0 & 1 & 0 \\
0 & 0 & 0 & 1
\end{array}\right) . \\
\mathcal{M}_{\mathcal{R}_{T H}^{\prime} / \mathcal{R}_{T H}} & =\left(\begin{array}{cccc}
1 & 0 & 0 & 0 \\
0 & \cos \left(\gamma^{T H}\right) & -\sin \left(\gamma^{T H}\right) & 0 \\
0 & \sin \left(\gamma^{T H}\right) & \cos \left(\gamma^{T H}\right) & 0 \\
0 & 0 & 0 & 1
\end{array}\right) .
\end{aligned}
$$

Global shape of the cutting edge (Fig. 1).

$$
\begin{gathered}
\mathcal{M}_{\mathcal{R}_{T H} / \mathcal{R}_{\theta}^{O}}(\theta)=\left(\begin{array}{cccc}
\cos \left(\frac{\pi}{2}-\theta\right) & 0 & \sin \left(\frac{\pi}{2}-\theta\right) & 0 \\
0 & 1 & 0 & 0 \\
-\sin \left(\frac{\pi}{2}-\theta\right) & 0 & \cos \left(\frac{\pi}{2}-\theta\right) & 0 \\
0 & 0 & 0 & 1
\end{array}\right) . \\
\mathcal{M}_{\mathcal{R}_{\theta}^{O} / \mathcal{R}_{\theta}^{M}}=\left(\begin{array}{cccc}
1 & 0 & 0 & 0 \\
0 & 1 & 0 & 0 \\
0 & 0 & 1 & -r_{\epsilon} \\
0 & 0 & 0 & 1
\end{array}\right) .
\end{gathered}
$$

Local cutting geometry - may depend on $\theta$ (Fig. 2) -.

$$
\begin{aligned}
\mathcal{M}_{\mathcal{R}_{\theta}^{M} / \mathcal{R}_{\gamma}} & =\left(\begin{array}{cccc}
1 & 0 & 0 & 0 \\
0 & \cos \left(\gamma_{n}^{E}\right) & -\sin \left(\gamma_{n}^{E}\right) & 0 \\
0 & \sin \left(\gamma_{n}^{E}\right) & \cos \left(\gamma_{n}^{E}\right) & 0 \\
0 & 0 & 0 & 1
\end{array}\right) . \\
\mathcal{M}_{\mathcal{R}_{\theta}^{M} / \mathcal{R}_{\alpha}} & =\left(\begin{array}{cccc}
1 & 0 & 0 & 0 \\
0 & \cos \left(-\frac{\pi}{2}-\alpha_{n}^{E}\right) & -\sin \left(-\frac{\pi}{2}-\alpha_{n}^{E}\right) & 0 \\
0 & \sin \left(-\frac{\pi}{2}-\alpha_{n}^{E}\right) & \cos \left(-\frac{\pi}{2}-\alpha_{n}^{E}\right) & 0 \\
0 & 0 & 0 & 1
\end{array}\right) .
\end{aligned}
$$

Therefore, the matrix transformations from $\mathcal{R}_{m}$ to $\mathcal{R}_{\gamma}$ and $\mathcal{R}_{\alpha}$ can be calculated as following:

$$
\mathcal{M}_{\mathcal{R}_{m} / \mathcal{R}_{i}}=\mathcal{M}_{\mathcal{R}_{m} / \mathcal{R}_{T H}^{\prime}} \mathcal{M}_{\mathcal{R}_{T H}^{\prime} / \mathcal{R}_{T H}} \mathcal{M}_{\mathcal{R}_{T H} / \mathcal{R}_{\theta}^{O}}(\theta) \mathcal{M}_{\mathcal{R}_{\theta}^{O} / \mathcal{R}_{\theta}^{M}} \mathcal{M}_{\mathcal{R}_{\theta}^{M} / \mathcal{R}_{i}} \text { with } i=\alpha, \gamma
$$

Coordinates of the current points and the local systems $\mathcal{R}_{i}(i=\alpha, \gamma)$ in the machine-tool system $\mathcal{R}_{m}$ can be determined:

$$
M(\theta)=\left(\begin{array}{c}
x(\theta) \\
y(\theta) \\
z(\theta) \\
1
\end{array}\right)_{\mathcal{R}_{m}}=\mathcal{M}_{\mathcal{R}_{m} / \mathcal{R}_{i}}\left(\begin{array}{l}
0 \\
0 \\
0 \\
1
\end{array}\right)_{\mathcal{R}_{i}} .
$$




$$
\begin{gathered}
\mathbf{a}(\theta)=\left(\begin{array}{l}
x_{a}(\theta) \\
y_{a}(\theta) \\
z_{a}(\theta) \\
0
\end{array}\right)_{\mathcal{R}_{m}}=\mathcal{M}_{\mathcal{R}_{m} / \mathcal{R}_{i}}\left(\begin{array}{l}
1 \\
0 \\
0 \\
0
\end{array}\right)_{\mathcal{R}_{i}} . \\
\mathbf{n}_{\mathbf{i}}(\theta)=\left(\begin{array}{l}
x_{n}(\theta) \\
y_{n}(\theta) \\
z_{n}(\theta) \\
0
\end{array}\right)_{\mathcal{R}_{m}}=\mathcal{M}_{\mathcal{R}_{m} / \mathcal{R}_{i}}\left(\begin{array}{l}
0 \\
1 \\
0 \\
0
\end{array}\right)_{\mathcal{R}_{i}} . \\
\mathbf{g}_{\mathbf{i}}(\theta)=\left(\begin{array}{l}
0 \\
x_{g}(\theta) \\
y_{g}(\theta) \\
z_{g}(\theta) \\
0
\end{array}\right)_{\mathcal{R}_{m}}=\mathcal{M}_{\mathcal{R}_{m} / \mathcal{R}_{i}}\left(\begin{array}{l}
0 \\
1 \\
0
\end{array}\right)_{\mathcal{R}_{i}} .
\end{gathered}
$$

Results of the geometrical modeling. According to the paragraph on matrix transformation, the cutting geometry is defined in the machine coordinate system, in which tool/workpiece relative motions are given. So, the working cutting geometry - planes and angles of the toolin-use system [10] - can be known at each point $M$ of the discretisation. Let $\mathbf{v}_{\mathbf{c}}, \mathbf{v}_{\mathbf{f}}, \mathbf{v}_{\mathbf{e}}$ be respectively the local cutting, feed and effective cutting speeds.

\section{Planes of the tool-in-use system.}

$$
\begin{array}{lll}
P_{r e} \perp \mathbf{v}_{\mathbf{e}} . & (12) & P_{s e}=\left(\mathbf{v}_{\mathbf{e}}, \mathbf{a}\right) . \\
P_{f e}=\left(\mathbf{v}_{\mathbf{c}}, \mathbf{v}_{\mathbf{f}}\right) . & \text { (13) } \quad P_{n e}=\left(\mathbf{n}_{\gamma}, \mathbf{g}_{\gamma}\right)=P_{n} .
\end{array}
$$

Angles of the tool-in-use system.

$$
\begin{gathered}
\gamma_{n e}=\left(A_{\gamma}, P_{r e}\right)_{P_{n}}=\left(\mathbf{v}_{\mathbf{e}}^{\perp P_{n}}, \mathbf{n}_{\gamma}\right) . \\
\alpha_{n e}=\left(A_{\alpha}, P_{s e}\right)_{P_{n}}=\left(\mathbf{v}_{\mathbf{e}}^{\perp P_{n}}, \mathbf{g}_{\alpha}\right) .
\end{gathered}
$$

$$
\begin{aligned}
& \lambda_{s e}=\left(P_{r e}, \mathbf{a}\right)_{P_{s e}}=\left(\mathbf{v}_{\mathbf{e}}, \mathbf{a}\right)-\frac{\pi}{2} . \\
& \kappa_{r e}=\left(P_{s e}, P_{f e}\right)_{P_{r e}}=\left(\mathbf{v}_{\mathbf{f}}^{\perp P_{r e}}, \mathbf{a}^{\perp P_{r e}}\right) .
\end{aligned}
$$

The notation $\mathbf{v}_{\mathbf{i}}{ }^{\perp P_{j}}$ means the orthogonal projection of the vector $\mathbf{v}_{\mathbf{i}}$ on the plane $P_{j}$.

Let us consider two examples of configurations:

- Example (a): a RNGN09 round insert with a CRSN tool holder: $\lambda^{T H}=-6^{\circ}, \gamma^{T H}=-6^{\circ}, \gamma_{n}^{E}=0^{\circ}, \alpha_{n}^{E}=0^{\circ}$.

- Example (b): a RCGX10-AL [12] insert with a SRDCN tool holder: $\lambda^{T H}=0^{\circ}, \gamma^{T H}=0^{\circ}, \gamma_{n}^{E}=20^{\circ}, \alpha_{n}^{E}=7^{\circ}$.

The results obtained for these examples, in the case of cylindrical turning with $f=0.2 \mathrm{~mm} / \operatorname{tr}$ and $a_{p}=1.5 \mathrm{~mm}$, are presented on Fig. 3 and Fig. 4. Differences between global angles $\gamma^{T H}$, $\lambda^{T H}$ and local angles $\gamma_{n}^{E}, \alpha_{n}^{E}$ are clearly shown. 


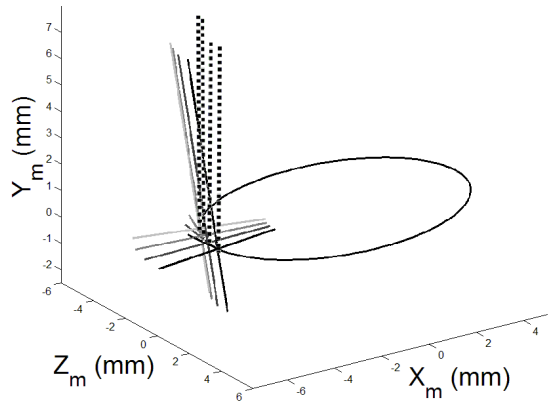

(a)

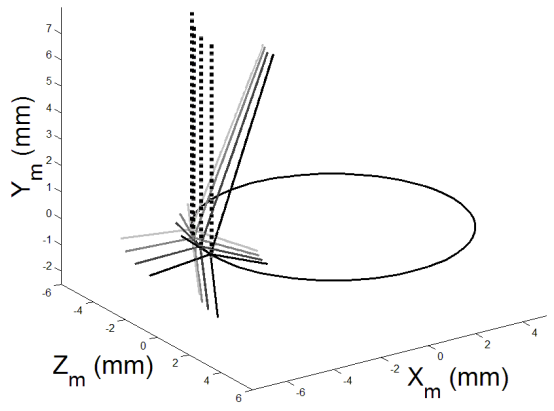

(b)

Fig. 3: 3D representation in $\mathcal{R}_{m}: \mathcal{R}_{\gamma}$ and $\mathcal{R}_{\alpha}$ (colour shading) and $\mathbf{v}_{\mathbf{e}}$ (dotted-line).

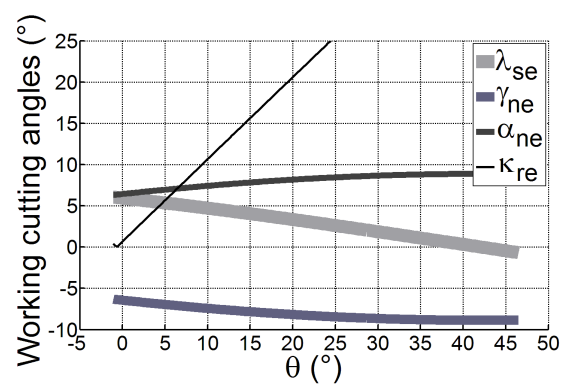

(a)

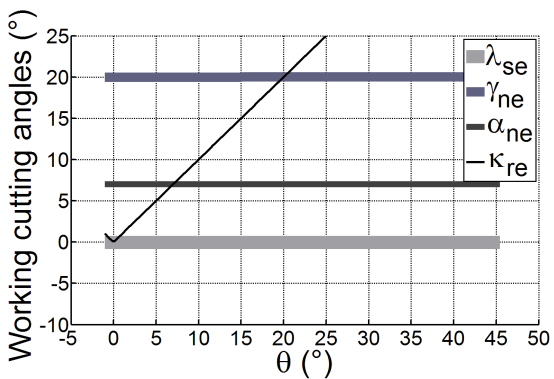

(b)

Fig. 4: Working cutting angles along the active cutting edge.

Since the working cutting geometry is known, it is possible to take it into account in the cutting forces relations [4]. Another interest of this model is the possibility of evaluating the moments easily.

\section{Cutting model in the case of Inconel 718 cylindrical turning}

The aim of this section is to build a local cutting model expressed in $\mathcal{R}_{\gamma}$ and $\mathcal{R}_{\alpha}$, which allows calculating the global cutting forces $F_{c}\left(\right.$ or $\left.F_{Y}\right), F_{f}$ (or $F_{Z}$ ) and $F_{p}$ (or $F_{X}$ ) in $\mathcal{R}_{m}$ (in which measurements are made). The study is limited to the cylindrical turning of Inconel 718 (Specified characteristics: $R_{m}>1275 \mathrm{MPa}$, Hardness 346-450 HB, Grain size 7-9 ASTM) in finishing and semi-finishing conditions with only one type of insert (cutting geometry is fixed).

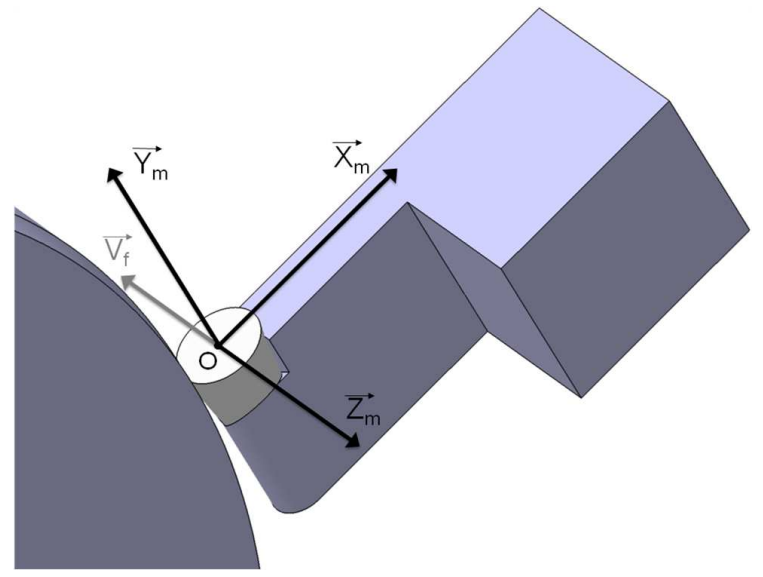

Fig. 5: The case study: cylindrical turning.

Experimental achievement. The insert used is a RCGX $090700 \mathrm{~F}\left(r_{\epsilon}=4.7625 \mathrm{~mm}\right)$ in Seco carbide grade CP200 (PVD coating (Ti, Al)N + TiN) assembled with a CRDCL 2025 P09AJ3M. This configuration gives the following values of parameters: $\lambda^{T H}=0^{\circ}, \gamma^{T H}=0^{\circ}, \gamma_{n}^{E}=$ $0^{\circ}, \alpha_{n}^{E}=7^{\circ}$. 
The tests have been conducted on a 2-axis lathe SOMAB T400. A piezo-electric dynamometer Kistler type 9121 with a charge amplifier type 5019B were used to measure the cutting forces - with an acquisition frequency of $1 \mathrm{kHz}$. Static calibration [11] is given in Table 1; the signalto-noise ratio is acceptable.

According to the Tool Material Pair methodology [4,15], the cutting speed has been fixed at $85 \mathrm{~m} / \mathrm{min}$. At this speed, the wear is extremely fast; for this reason, tests have been conducted with a particular attention to the cutting time.

Variables. Only the uncut chip thickness $h$ is considered as a variable in the model; it is calculated numerically (Fig. 6) in the plane $P_{r}$ which corresponds to the rake face and is close to $P_{r e}$. No projections [14] have been done.

Working cutting geometry will be introduced in the cutting relations in future work. Therefore, in the present study, chip flow angle [16] is not taken into account $\left(\lambda_{s e}(\theta)=0^{\circ} \forall \theta\right)$.

Due to the edge shape, the value of $h$ depends on both the feed $f$ and the depth of cut $a_{p}$.

Table 2: Experimental parameters and measurements.

Table 1: Static calibration of the dynamometer.

\begin{tabular}{|c|c|c|c|}
\hline & $F_{p}$ & $F_{f}$ & $F_{c}$ \\
\hline $\begin{array}{c}\text { Calibrated } \\
\text { range }[\mathrm{kN}]\end{array}$ & $0-3$ & $0-3$ & $0-6$ \\
\hline $\begin{array}{c}\text { Sensitivity } \\
{[\mathrm{pC} / \mathrm{N}]}\end{array}$ & -7.824 & -7.736 & -3.826 \\
\hline $\begin{array}{c}\text { Linearity } \\
{[< \pm \% \text { FSO }]}\end{array}$ & 0.05 & 0.16 & 0.15 \\
\hline $\begin{array}{c}\text { Cross Talk } \\
{[\%]}\end{array}$ & -0.7 & 2.2 & -0.3 \\
\hline
\end{tabular}

\begin{tabular}{|c|c|c|c||c|c|c|}
\hline & \multicolumn{3}{|c||}{ Parameters } & \multicolumn{3}{c|}{ Measured forces } \\
\hline Test & $t_{c}$ & $f$ & $a_{p}$ & $F_{c}$ & $F_{f}$ & $F_{p}$ \\
\hline$n_{T}$ & {$[\mathrm{~s}]$} & {$[\mathrm{mm} / \mathrm{rv}]$} & {$[\mathrm{mm}]$} & {$[\mathrm{N}]$} & {$[\mathrm{N}]$} & {$[\mathrm{N}]$} \\
\hline 1 & 10 & 0.1 & 0.1 & 90 & 20 & 163 \\
\hline 2 & 20 & 0.1 & 0.85 & 397 & 174 & 513 \\
\hline 3 & 30 & 0.15 & 0.55 & 430 & 156 & 515 \\
\hline 4 & 40 & 0.15 & 0.7 & 455 & 158 & 523 \\
\hline 5 & 50 & 0.1 & 0.4 & 237 & 76 & 352 \\
\hline 6 & 60 & 0.15 & 0.25 & 215 & 50 & 306 \\
\hline 7 & 10 & 0.2 & 0.85 & 619 & 212 & 637 \\
\hline 8 & 20 & 0.2 & 0.1 & 119 & 20 & 190 \\
\hline 9 & 30 & 0.25 & 0.7 & 603 & 178 & 613 \\
\hline 10 & 40 & 0.2 & 0.55 & 428 & 132 & 517 \\
\hline 11 & 50 & 0.25 & 0.25 & 261 & 55 & 337 \\
\hline 12 & 60 & 0.25 & 0.4 & 373 & 91 & 443 \\
\hline
\end{tabular}

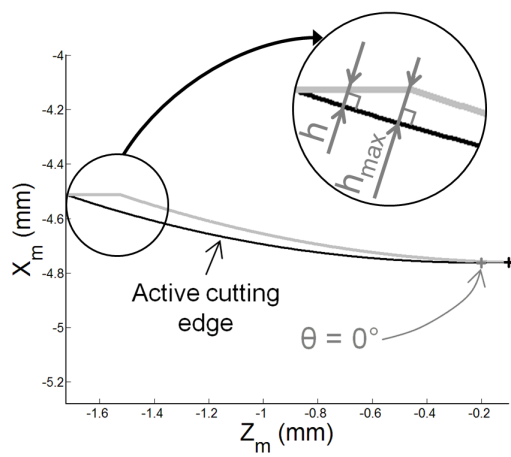

(a)

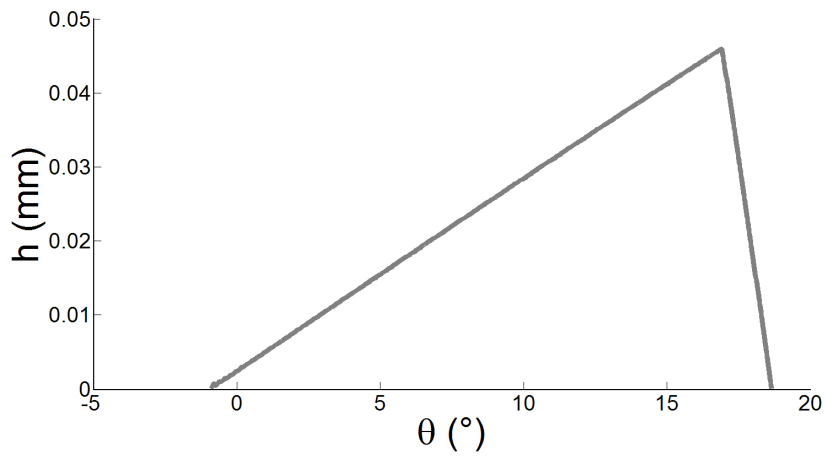

(b)

Fig. 6: $f=0.2 \mathrm{~mm} / \operatorname{tr}$ and $a_{p}=0.25 \mathrm{~mm}$ : (a) Cross section of undeformed chip;

(b) Uncut chip thickness along the active cutting edge.

An orthogonal design of experiment, including cutting time $t_{c}$ in addition to $f$ and $a_{p}$ [1], has been used (Table 2). So, the parameters $f$ and $a_{p}$ are distributed independently of each other, and there is no link between the variation of these parameters and the variation of wear. 
Cutting model. The local cutting forces applied on a segment (Fig. 7) are assumed to follow the equations (20) to (23).

The hypothesis of independence of the segments can be done, because of the size of the insert and the shape of the rake face (a plane).

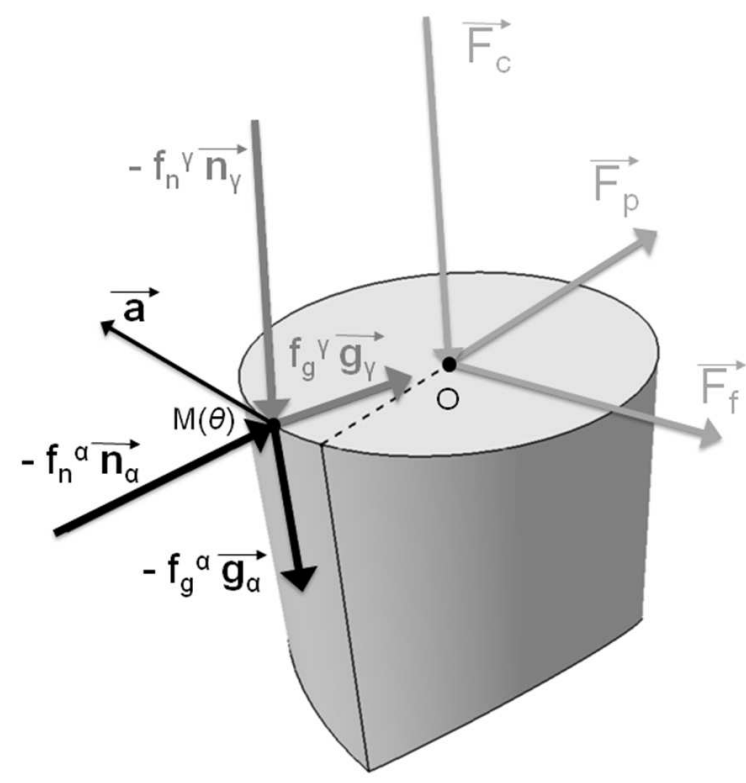

$$
\begin{aligned}
& f_{n}^{\gamma}=K_{n}^{\gamma} \cdot h(\theta) \cdot\left[1+e^{-\left(\frac{h(\theta)}{h_{0}}\right)^{m}}\right] . \\
& f_{g}^{\gamma}=C_{f}^{\gamma} \cdot\left|f_{n}^{\gamma}\right| . \\
& f_{n}^{\alpha}=k_{n}^{\alpha} . \\
& f_{g}^{\alpha}=C_{f}^{\alpha} \cdot\left|f_{n}^{\alpha}\right| .
\end{aligned}
$$

Fig. 7: Local linear forces $\left(f_{n}^{\gamma}, f_{g}^{\gamma}, f_{n}^{\alpha}, f_{g}^{\alpha}\right)$

and global cutting forces $\left(F_{c}, F_{f}, F_{p}\right)$.

At small uncut chip thickness (preponderant parameter), cutting forces are non-linear.

A size effect function based on a Weibull function, proposed by Ko and Cho [3], is prefered to the classical Kienzle-Victor model $[8,13]$.

In a first approximation, the normal force on the clearance face $f_{n}^{\alpha}$ is kept constant (Eq. (22)).

Tangential forces are calculated with Coulomb's friction law (Eq. (21) and (23)).

It can be noticed that Eq. (20) integrates only three coefficients and not four [3] in order to reduce the degrees of freedom of the model.

Inverse identification. Inverse identification consists in comparing calculated (by summation) global values with measured global values, in order to determine local coefficients.

In the present study, the 36 measured global forces (Table 2) are compared to the global forces given by the integration (calculated for the same set of parameters $\left(f\right.$ and $\left.a_{p}\right)$ ).

In order to determine the best combination of the 6 coefficients $\left(K_{n}^{\gamma}, h_{0}, m, C_{f}^{\gamma}, k_{n}^{\alpha}, C_{f}^{\alpha}\right)$, a criterion should be chosen and minimized. For example, it could be the sum of squared deviations or a weighted overall error [7]; absolute or relative errors could be considered.

The criterion $\mathrm{W}$ used in this study is the sum of the maxima of the relative deviations on the whole tests for $F_{c}$ and $F_{p}$ (Eq. 24); $F_{f}$ is neglected, so this criterion can be considered as weighted.

$$
W=\max _{n_{T}}\left(\Delta F_{c}^{R}\right)+\max _{n_{T}}\left(\Delta F_{p}^{R}\right) .
$$


The identification gives the following values of the coefficients (incertitudes correspond to numerical step):

$$
\begin{aligned}
& K_{n}^{\gamma}=2410 \mathrm{~N} / \mathrm{mm}^{2} \pm 10 \\
& h_{0}=0.019 \mathrm{~mm} \pm 0.001 \\
& m=0.61 \pm 0.01
\end{aligned}
$$

$$
\begin{aligned}
& C_{f}^{\gamma}=0.48 \pm 0.01 \\
& k_{n}^{\alpha}=148 \mathrm{~N} / \mathrm{mm} \pm 1 . \\
& C_{f}^{\alpha}=0.52 \pm 0.01 .
\end{aligned}
$$

A comparison between modeled and measured cutting forces for the 12 tests is given in the Table 3 .

The average deviations are the following: $6.9 \%$ for $F_{c}, 4.8 \%$ for $F_{f}$ and $3.9 \%$ for $F_{p}$.

For the two main components, the maximum relative deviation is close to $10 \%$.

The chordal error is set arbitrarily equal to $1 \cdot 10^{-5} \mathrm{~mm}$ for all the calculations; so, the length of the segments is $19.4 \mu \mathrm{m}$.

Table 3: Absolute and relative deviations between the model and the measurements.

\begin{tabular}{|c|c|c|c|c|c|c|}
\hline & \multicolumn{3}{|c|}{ Absolute deviation } & \multicolumn{3}{|c|}{ Relative deviation } \\
\hline Test & $\Delta F_{c}^{A}$ & $\Delta F_{f}^{A}$ & $\Delta F_{p}^{A}$ & $\Delta F_{c}^{R}$ & $\Delta F_{f}^{R}$ & $\Delta F_{p}^{R}$ \\
$n_{T}$ & {$[\mathrm{~N}]$} & {$[\mathrm{N}]$} & {$[\mathrm{N}]$} & {$[\%]$} & {$[\%]$} & {$[\%]$} \\
\hline 1 & 7 & -2 & 14 & 7.4 & -11.3 & 8.6 \\
\hline 2 & 31 & 4 & 32 & 7.9 & 2.4 & 6.3 \\
\hline 3 & -45 & -36 & -44 & -10.7 & -22.9 & -8.6 \\
\hline 4 & 8 & -0 & 14 & 1.7 & -0.0 & 2.7 \\
\hline 5 & 9 & 2 & 14 & 4.0 & 2.7 & 4.0 \\
\hline 6 & -0 & 0 & -0 & -0.1 & 0.3 & -0.0 \\
\hline 7 & 29 & 3 & 12 & 4.7 & 1.3 & 1.9 \\
\hline 8 & 13 & -1 & 10 & 10.7 & -3.8 & 5.3 \\
\hline 9 & 43 & 7 & 14 & 7.2 & 3.8 & 2.2 \\
\hline 10 & 30 & -2 & -10 & 6.9 & -1.7 & -1.9 \\
\hline 11 & 27 & 1 & 10 & 10.5 & 1.5 & 3.0 \\
\hline 12 & 40 & 5 & 10 & 10.7 & 5.4 & 2.2 \\
\hline
\end{tabular}

Analysis of the model and its results. The order of magnitude of the identified coefficient $h_{0}$ (Eq. 26) is the same as the one of the cutting edge radius $r_{\beta}$.

$C_{f}^{\gamma}$ is smaller than $C_{f}^{\alpha}$ (Eq. 28 and 30), which can be explained by the higher temperature on the rake face; however, the difference is weak.

Then, two cases are considered:

- Case (a): finishing conditions: $f=0.1 \mathrm{~mm} / \mathrm{rv} ; a_{p}=0.25 \mathrm{~mm}$

- Case (b): semi-finishing conditions: $f=0.25 \mathrm{~mm} / \mathrm{rv} ; a_{p}=0.85 \mathrm{~mm}$

The evolutions of local cutting forces along the cutting edge, for these cases, are presented on Fig. 8. The evolution of local forces applied on the rake face $f_{n}^{\gamma}$ and $f_{g}^{\gamma}$ (Fig. 8) is near the evolution of h (Fig. 6 (b)). 


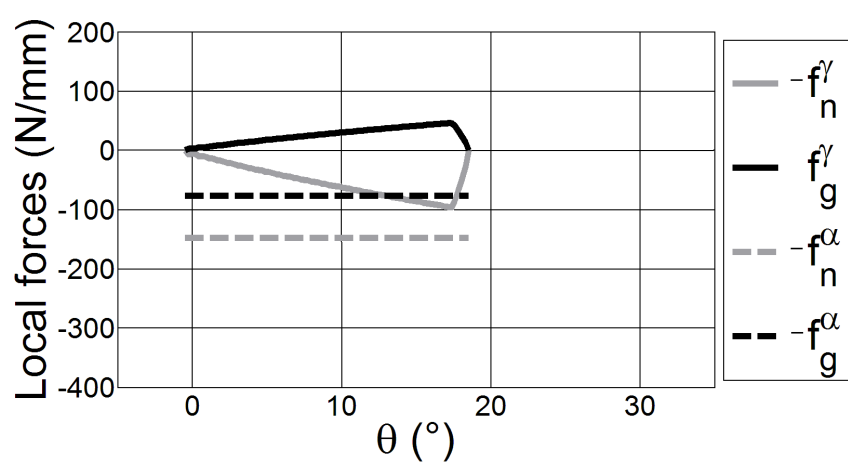

(a)

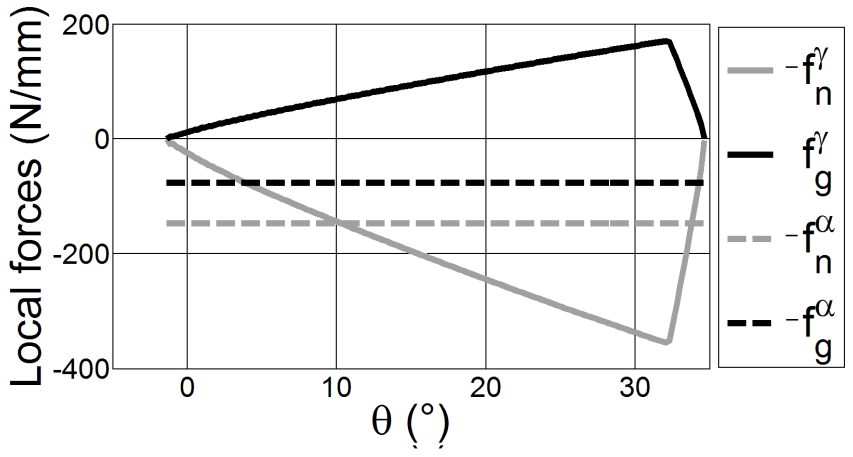

(b)

Fig. 8: Local cutting forces along the active cutting edge.

In the first case, the sum of the forces applied on $A_{\alpha}$ is higher than that applied on $A_{\gamma}$, whereas it is the opposite in the second case. Fig. 9 shows the contribution of each local component on global forces.

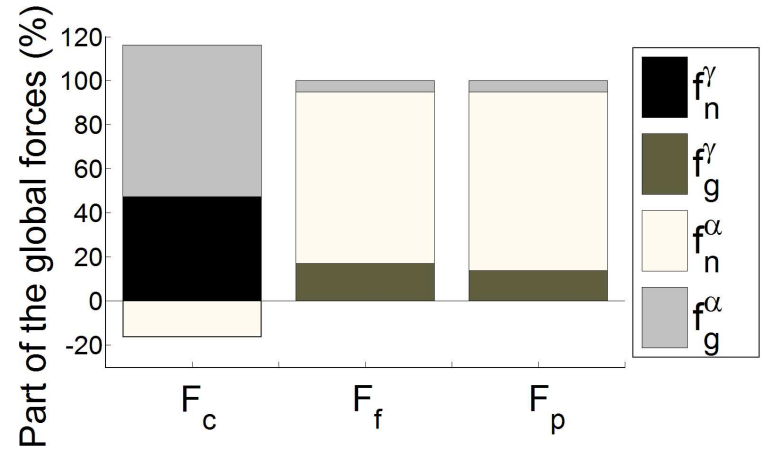

(a)

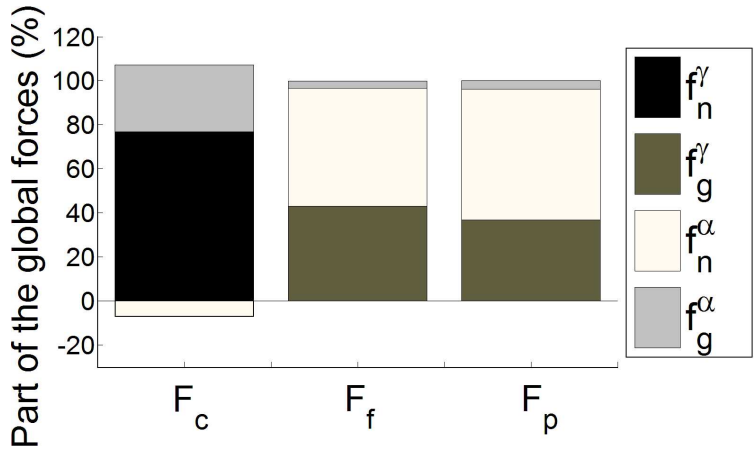

(b)

Fig. 9: Contribution of local forces to global calculated forces.

The identified coefficient $K_{n}^{\gamma}$ (Eq. 25) is less than the order of magnitude of the specific cutting force $K_{c}$ (higher than $4000 \mathrm{~N} / \mathrm{mm}^{2}$ ). It is due to the calculation of $K_{c}$ which does not consider the flank effects. The contribution of these effects to $F_{c}$ could be higher than $50 \%$ (Fig. 9 ). It seems that the validity domain of the formula $F_{c}=K_{c} \cdot A_{D}$ is only roughing operations.

Concerning $F_{f}$ and $F_{p}$, the major part comes from the contact between the workpiece and the clearance face, which decreases in favor of the friction on $A_{\gamma}$ when $h$ increases.

\section{Conclusion}

In this paper, a geometrical model based on homogeneous matrix transformation is presented. It is available for turning operations with round inserts and allows taking into account the flank effects which are not negligible for these tools. This model will be generalized for other turning operations, and even for other processes.

Even if the principle of independence of the segments is an assumption in the case of round inserts, the proposed cutting model with 6 coefficients allows determining global cutting forces with a low error in a large domain of feed and depth of cut.

The experimental approach is helpful to identify cutting laws in the case of fast wear. The inverse identification does not permit to verify the form of the cutting model and the values of the coefficients, contrary to orthogonal or oblique cutting tests. However, the macroscopic 
results are satisfactory and a physical interpretation could be given at the identified coefficients.

Future work will introduce working geometry [4] and material parameters in cutting relations when modeling profile turning. Then, other characteristics - as edge preparation - will be taken into account.

\section{References}

[1] W.A. Kline, R.E. Devor and J.R. Lindberg: International Journal of Machine Tool Design and Research Vol. 22/1 (1982), p. 7-22.

[2] Y. Altintas and P. Lee: CIRP Annals Manufacturing Technology, Vol. 45/1 (1996), p. 59-64.

[3] J.H. Ko and D.-W. Cho: Journal of Manufacturing Science and Engineering, Vol. 127 (2005), p. 1-11.

[4] S. Bissey-Breton, G. Poulachon, and F. Lapujoulade: Journal of Engineering Manufacture, Vol. 4 (2006), p. 579-587.

[5] G. Yücesan, and Y. Altintas: ASME Journal of Engineering for Industry, Vol. 118 (1996), p. 95103.

[6] F. Meslin, and J.C. Hamann: Proceeding of the CIRP International Workshop on Friction and Flow Stress in Cutting and Forming, Paris (2000), p. 135-157.

[7] J. Pujana, P.J. Arrazola, R. M'Saoubi, and H. Chandrasekaran: International Journal of Machine Tools \& Manufacture, Vol. 47 (2007), p. 2153-2161.

[8] O. Kienzle, and H. Victor: VDI-Z 94/11-12, Düsseldorf (1952), p. 299-305.

[9] International Organization for Standardization: Industrial Automation Systems and Integration Numerical Control of Machines - Coordinate System and Motion Nomenclature, ISO 841 (2004).

[10] International Organization for Standardization: Basic Quantities in Cutting and Grinding Part 1, ISO 3002-1 (1993).

[11] V.P. Astakhov, in: Metal Cutting Mechanics, edited by CRC Press (1999).

[12] Sandvik Coromant, in: Modern Metal Cutting (1994).

[13] B. Denkena and J. Köhler: Machining Science and Technology, Vol. 14/4 (2010), p. 455-470.

[14] T. Carlsson, and T. Stjernstoft: CIRP Annals Manufacturing Technology, Vol. 50/1 (2001), p. 4144.

[15] French Standard: Working Zones of Cutting Tools - Couple Tool-Material - Part 4, AFNOR NF E 66-520-4, ISSN 0335-3931 (1997).

[16] G.V. Stabler: Proceedings of the Institution of Mechanical Engineers (1951), p. 14-26. 